\title{
Nonlinearity, Liquefaction, and Velocity Variation of Soft Soil Layers in Port Island, Kobe, during the Hyogo-ken Nanbu Earthquake
}

\author{
by Jorge Aguirre and Kojiro Irikura
}

\begin{abstract}
Clear nonlinear behavior is analyzed from the acceleration records of the 1995 Hyogo-ken Nanbu earthquake at Port Island, Kobe. From four triaxial instruments placed at four different depths, the surficial effects during strong ground motions were compared with those during weak motions before and after the mainshock. We used a spectral ratio technique and a nonlinear inversion for velocity structure to analyze the data. From the spectral analysis, we observed a large variation of the spectral ratios between the surface and different depths during the strong ground motions and during the liquefied state. The spectral ratios after the mainshock (i.e., after the liquefied state) are different from those before the mainshock. The peak frequencies in the spectral ratios after the mainshock are shifted to lower frequencies with respect to those in the spectral ratios before the mainshock. We inverted the $S$-wave velocities using a genetic algorithm technique to determine the velocity structure before, during, and after the mainshock. The $S$-wave velocity structure before and after the mainshock was found to be different. Specifically, the $S$ wave velocity of the second layer ( $5 \mathrm{~m}$ to $16 \mathrm{~m}$ depth) after the mainshock was $20 \%$ lower than before. Our analysis shows that the liquefied state remains at least $3 \mathrm{hr}$ after the mainshock but no more than $24 \mathrm{hr}$. The rigidity of the soil decreased close to zero when liquefaction happened and later increases gradually following a trend that resembles a consolidation curve. The strong influence of nonlinearity during the mainshock yielded a big reduction of the horizontal surface ground motions, so that the observed horizontal peak acceleration was only about $25 \%$ of the peak acceleration expected from the linear theory. However, the nonlinear effects in the vertical peak acceleration were not significant.
\end{abstract}

\section{Introduction}

Many authors have been studying the amplification produced from the sedimentary soils in order to predict the motions during large earthquakes, as well as to reproduce the ground motions during large earthquakes at sites where the ground motions have not been recorded. The amplification of the seismic waves basically originates from the strong contrast between the physical properties of the rocks and the sediments. To evaluate this amplification, conventionally, the seismic response of the soils has been treated as linear in the seismological community. That means strain and stress are related linearly by a constant rigidity independently of the level of strain. This assumption is acceptable for low levels of strain (for $\gamma_{c}=0.0001 \%$ and $0.001 \%$, where $\gamma_{c}$ is the cyclic shear strain amplitude, Vucetic and Dobry, 1991), from soil laboratory testing results. But for larger stress-strain levels, the soil laboratory testing results showed a nonlinear relation, that is, the nonlinear character of the soil response.

The basic reason that the seismologist conventionally has been using a linear relation is that for the level of strains in most of the seismological observations the shear modulus reduction is small. But, according to the laboratory test results, the nonlinear relation in the case of large strains may play an important role in ground motions at soil sites near the source during large earthquakes. Since the conditions in the laboratory are not the same to those in the field, it is important to investigate the nonlinearity of the soil response for large strain levels through in situ observations by separating the soil response from other factors such as source and path effects in seismic data.

Some authors have been trying to find observational proof of the nonlinearity from seismological data and estimate how much it influences strong ground motions (Sugito and Kameda, 1990; Chin and Aki, 1991; Ordaz and Faccioli, 1994; Aguirre et al., 1994; Beresnev et al., 1995; Satoh et al., 1995). One of the problems that they have been facing is the lack of records for large strain levels during the strong ground motions. Also, the mixed influence of the nonlinear 
soil response to the recorded motion and other effects makes it difficult to study accurately. Since the nonlinear effect typically occurs in unconsolidated soft soils, our analysis should be focused on very surficial layers. Then, in order to study the nonlinear effect from the seismological point of view, it is necessary to extract the local site effects from the observed records. There are several ways to overcome these problems. The transfer function of seismic waves in soil layers is estimated by calculating the spectral ratio between the motion at the soil surface and the motion at the basement underlying the soil layers. In many studies, the rock outcrop motion is used to estimate the motion at the basement. That is an approximation for the real motion at the basement under the soil layers; the accuracy of this approximation depends on the simplicity of the topographical conditions around rock outcrop station. In most of the cases, the surface topography at the rock outcrop site is very complex.

Another option for estimating the soil layers effect is to use data from a vertical array of seismometers. Using the records from the vertical arrays, it is possible to separate the site effect from the source and path effects and then verify the behavior of the soil layers between the stations at different depths whenever an earthquake is recorded. So it is possible to identify the nonlinear behavior and the changes of the physical properties in the layers with the lapsed time. Unfortunately, the borehole stations are not so widely deployed as surface stations. This is the reason why the nonlinear behavior has been difficult to identify. Even if the deeper borehole stations of the vertical array do not reach the basement, it is useful to separate the local effects at sites just where the nonlinear effects are expected to occur, in the unconsolidated soil layers closer to the surface.

Here, the Port Island vertical array data are used to study the nonlinear response and the time variation of the velocities of the soil layers that may be caused by the liquefaction during the intense part of the 1995 Hyogo-ken Nanbu earthquake as well as the variation of soil properties during the liquefaction state. First, the velocity structure model is precisely determined analyzing the five events before the mainshock by nonlinear inversion being revised from $P-S$ waves logging data. Next, the revised model is used to simulate the mainshock for the linear and nonlinear cases. The long-duration record during the mainshock is used to discuss the variation of the response within $6 \mathrm{~min}$ after the mainshock. Finally, the inversion of the velocity structure for the aftershocks was made. The purpose of this article is to discuss the time variation of local site effects and its influence on the ground motion.

\section{Array and Data}

The array is composed of four triaxial accelerometers placed at GL-0 m, GL-16 m, GL-32 m, and GL-83 m, where GL means "ground level," hereafter identified as PR4, PR3, PR2, and PR1, respectively. The original velocities, type of soil, and positions of the sensors are shown in Table 1 (De- velopment Bureau, Kobe City, 1991). Since the horizontal components of the instrument placed at $83 \mathrm{~m}$ depth deviate $19^{\circ}$ in clockwise direction as studied by Ansary et al. (1995), we correct all of the records that we used in this study, applying a rotation of $19^{\circ}$ in the opposite direction.

The set of records used here is shown in the Table 2. It consists of records from five earthquakes occurring in 1994 before the mainshock, the long-duration $(6 \mathrm{~min})$ record of the mainshock, and 12 aftershocks occurring $3 \mathrm{hr}$ to 10 months after the mainshock. The epicentral locations of all of these earthquakes are shown in Figure 1. The record of the mainshock with a duration of $360 \mathrm{sec}$ was divided into nine sections, we refer to them as mainshock and sections A to $\mathrm{H}$. One example of this very long-duration record with the sections $\mathrm{A}$ to $\mathrm{H}$ is shown in Figure 2. The records of the $\mathrm{N}-\mathrm{S}$ component at $-16 \mathrm{~m}$ show an unusual behavior during the aftershocks from 1995/01/17 08:58 hr to $1995 / 05 / 19$

Table 1

Original Soil Model in Port Island Vertical Array

\begin{tabular}{ccccc}
\hline $\begin{array}{c}\text { Depth } \\
(\mathrm{m})\end{array}$ & Soil Type & $\begin{array}{c}\text { Location of } \\
\text { Accelerometers }\end{array}$ & $\begin{array}{c}V_{p} \\
{[\mathrm{~km} / \mathrm{sec}]}\end{array}$ & $\begin{array}{c}V_{s} \\
{[\mathrm{~km} / \mathrm{sec}]}\end{array}$ \\
\hline $0-2.0$ & & $* P R 4-0 \mathrm{~m}$ & 0.260 & 0.170 \\
$2.0-5.0$ & Gravel $^{\mathrm{R}}$ & & 0.330 & \\
$5.0-12.6$ & & & 0.780 & 0.210 \\
$12.6-19.0$ & Sandy gravel ${ }^{\mathrm{R}}$ & $* \mathrm{PR} 3-16 \mathrm{~m}$ & 1.480 & \\
$19.0-27.0$ & Clay & & 1.180 & 0.180 \\
$27.0-33.0$ & Sand & $* \mathrm{PR} 2-32 \mathrm{~m}$ & 1.330 & 0.245 \\
$33.0-50.0$ & Sandy gravel & & 1.530 & 0.305 \\
& and sand & & 1.610 & 0.350 \\
$50.0-61.0$ & Sand & & & 0.303 \\
$61.0-79.0$ & Clay & & & \\
$79.0-(85.0)$ & Sandy gravel & $* P R 1-83 \mathrm{~m}$ & 2.000 & 0.320 \\
\hline
\end{tabular}

$\mathrm{R}=$ Reclaimed land.

Table 2

Seismic Events Used in This Study

\begin{tabular}{cccc}
\hline $\begin{array}{c}\text { Date } \\
\text { (year.month.day) }\end{array}$ & $\begin{array}{c}\text { Time } \\
\text { (hr:min:sec) }\end{array}$ & $\begin{array}{c}\text { Depth } \\
(\mathrm{km})\end{array}$ & Magnitude \\
\hline 94.06 .28 & $13: 08: 53.02$ & 16.0 & 4.6 \\
94.07 .28 & $10: 01: 52.04$ & 11.5 & 4.1 \\
94.10 .24 & $11: 51: 10.72$ & 15.1 & 4.3 \\
94.11 .09 & $20: 26: 56.41$ & 10.4 & 4.1 \\
94.11 .10 & $00: 38: 17.72$ & 11.1 & 3.9 \\
95.01 .17 & $05: 46: 46.74$ & 16.0 & 6.9 \\
95.01 .17 & $08: 58: 16.14$ & 18.8 & 4.7 \\
95.01 .18 & $05: 25: 40.39$ & 9.56 & 3.0 \\
95.01 .26 & $01: 01: 18.38$ & 11.01 & 3.3 \\
95.02 .02 & $12: 57: 22.13$ & 5.94 & 2.4 \\
95.02 .02 & $16: 04: 19.55$ & 12.80 & 3.4 \\
95.02 .02 & $16: 19: 27.71$ & 17.24 & 3.4 \\
95.02 .03 & $20: 36: 55.32$ & 5.22 & 3.0 \\
95.02 .18 & $21: 37: 33.66$ & 20.42 & 3.8 \\
95.05 .04 & $17: 42: 02.18$ & 16.2 & 4.3 \\
95.05 .19 & $20: 35: 38.97$ & 20.8 & 4.1 \\
95.09 .12 & $06: 30: 26.41$ & 15.7 & 3.9 \\
95.10 .14 & $02: 03: 59.15$ & 16.8 & 4.8 \\
\hline
\end{tabular}




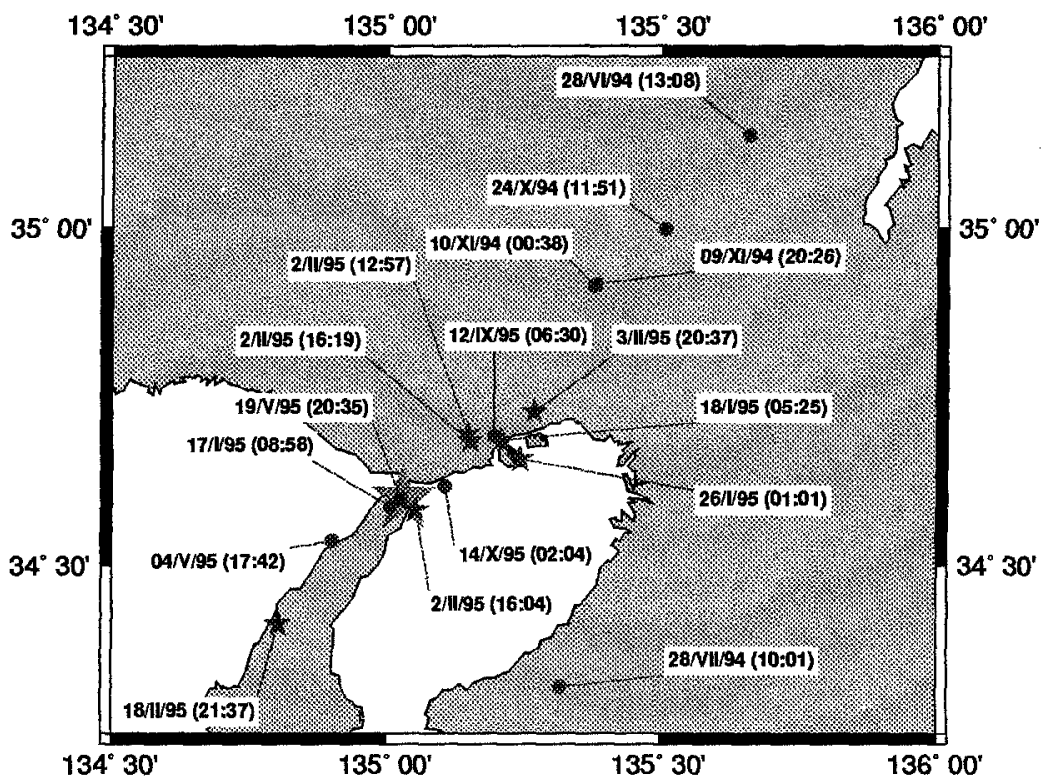

Figure 1. Epicentral location of the earthquakes in Table 2. Biggest star corresponds to the mainshock.
20:35 hr, probably because of a malfunction of the sensor. This sensor was replaced by a new one around 20 May 1995 . Those irregular data will not be used in this analysis.

\section{Method}

We analyze the variation of the $S$ wave's velocity structure on Port Island vertical array before, during, and after the mainshock by means of spectral ratios, correlation analysis, and nonlinear inversion of the velocity structure.

In the spectral ratio analysis, we choose the $S$-wave part in the records and compute the Fourier spectra. After smoothing the spectral amplitudes, the ratios PR4/PR3, PR4/ PR2, and PR4/PR1 are computed. For the linear case, that is, for the weak motions, we expect to obtain the same ratios from different earthquakes. In reality, the ratios have some variation basically due to the difference of the incidence angles and the heterogeneity of the medium. The linear transfer function could be considered as the average of these ratios. In order to discuss the change of the physical properties due to the liquefaction, we estimate two transfer functions, for the records of events before the mainshock and for those of aftershocks. In addition, the records during the mainshock are divided into two parts (see the left bottom of Fig. 2a): one before liquefaction and the other after liquefaction. The transfer functions during strong motions are estimated from the former, and those during liquefaction, from the latter. Further, the transfer functions during the liquefaction state are estimated from subsequent aftershocks included in the long-duration record and one aftershock occurring $3 \mathrm{hr}$ later.

The nonlinear inversion is based on the genetic algorithm (GA) technique in which the evaluation function compares the theoretical and observed transfer functions. In this case, the chromosomes are the velocities and damping coefficients for each layer. The performance of the individuals are evaluated by the normalized residual value obtained from the fitting of the observed and simulated transfer function by the revised Haskell-Thompson method with damping factors. After several generations, the performance of the best individuals are improved, and the normalized residuals reduced. Then the best individual of all generations with the smaller residual is taken as the result of the inversion. The range of velocities for each chromosome is fixed based on the original velocity structure model obtained from the boring data. The interval between 0 and $83 \mathrm{~m}$ is divided into eight layers with different $S$-wave velocities according to the original velocity structure. The allowed velocity for each layer ranges from 5 to $500 \mathrm{~m} / \mathrm{sec}$.

\section{Spectral Analysis}

For the analysis in the frequency domain, we select the $S$-wave part in the records and compute the Fourier spectra. After smoothing the spectral amplitudes, the ratios PR4/ PR3, PR4/PR2, and PR4/PR1 are computed. In Figure 3a, the ratios PR4/PR3 (surface/16 m depth) of the E-W component for the 11 aftershocks have been plotted as an example. The average of those ratios is plotted with the standard deviation in Figure 3b. The linear transfer function could be considered as the average of the ratios. We estimate the transfer functions as the averaged spectral ratios between stations PR4/PR3, PR4/PR2, and PR4/PR1 for the events recorded before the mainshock and for the aftershocks.

First, we calculate the ratios for $\mathrm{E}-\mathrm{W}$ and N-S components separately. The averaged ratios for the E-W component are very similar to those for the $\mathrm{N}-\mathrm{S}$ component for both before and after the mainshock, as shown in Figure 4. Therefore, the results of the analysis done for one component can be generalized for both $\mathrm{E}-\mathrm{W}$ and $\mathrm{N}-\mathrm{S}$ components. For the aftershocks, we consider the 11 events occurring after the mainshock from 18 January to 14 October 1995 . We exclude the event occurring about $3 \mathrm{hr}$ after the mainshock 
(a)

(a)
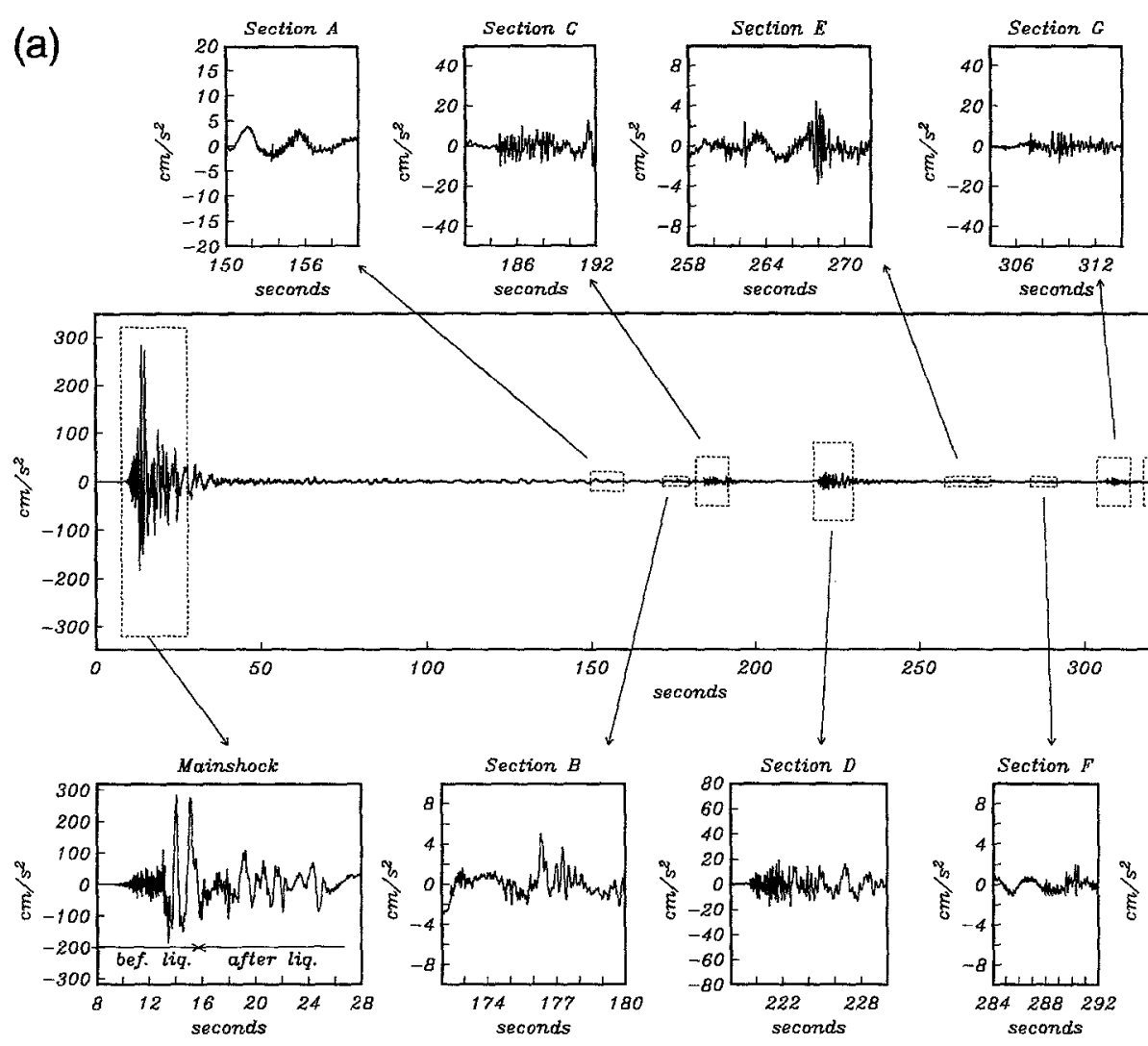
(a)

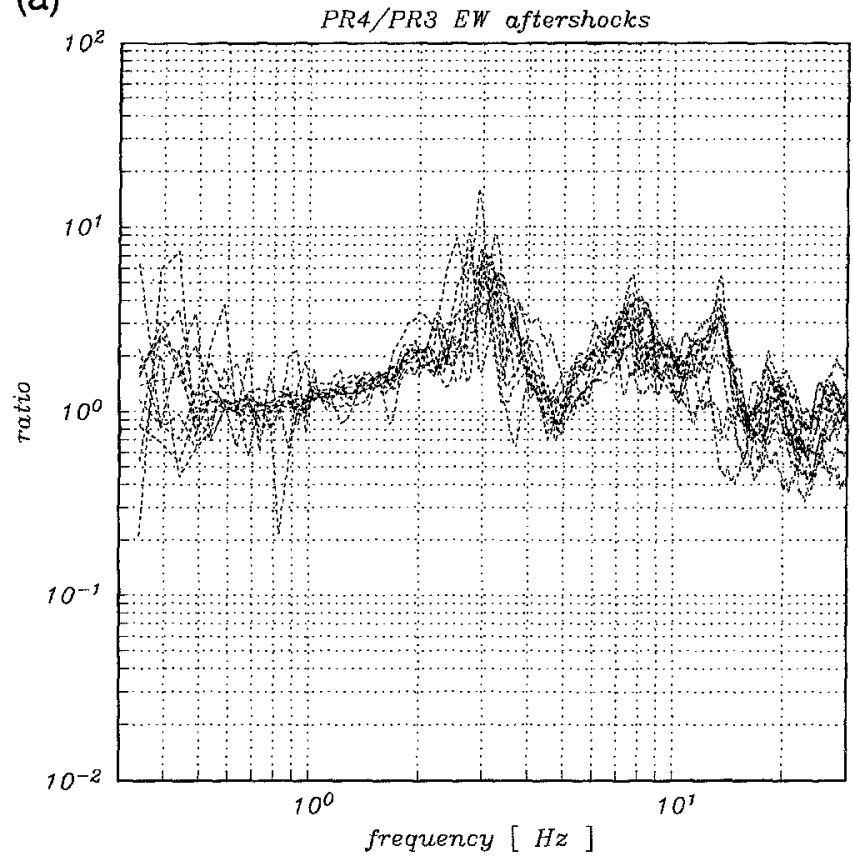

(b)

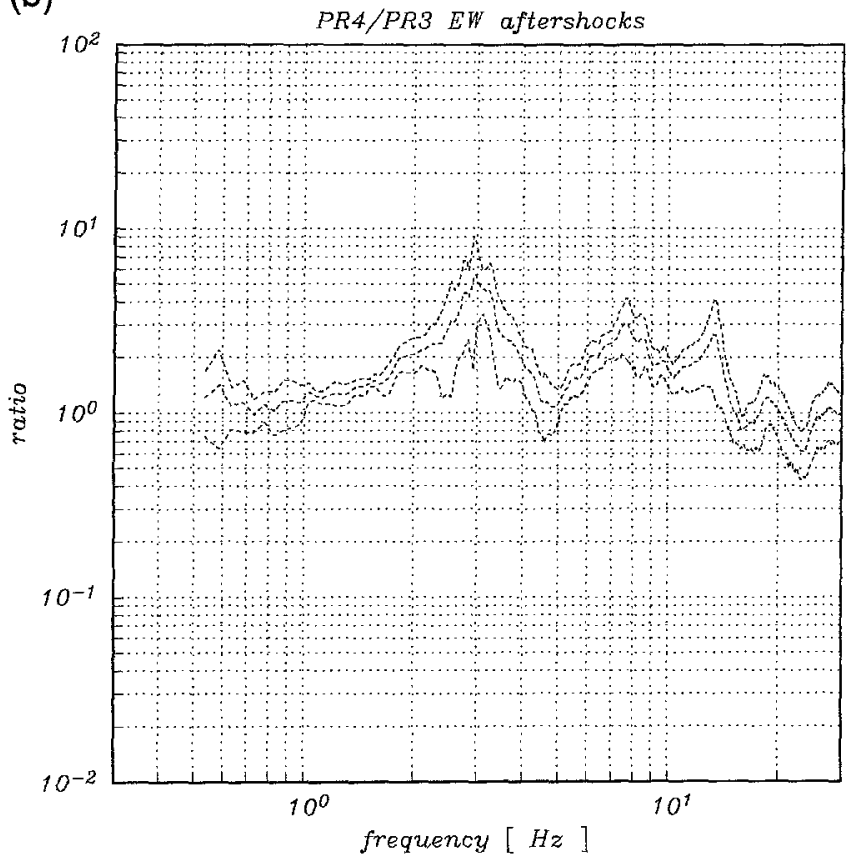

Figure 3. (a) Spectral ratios PR4/PR3 (E-W component) from 11 aftershocks and (b) the average and standard deviation for the same events.

because of its discrepancy from the rest of the ratios, probably due to the after effects of the liquefaction as later discussed. The spectral ratios PR4/PR3 for the N-S component from the events recorded after the mainshock until 19 May were excluded because of the malfunction of the sensor at $16 \mathrm{~m}$ depth (i.e., PR3). Then the transfer function PR4/PR3 for the $\mathrm{N}-\mathrm{S}$ component from the aftershocks is estimated
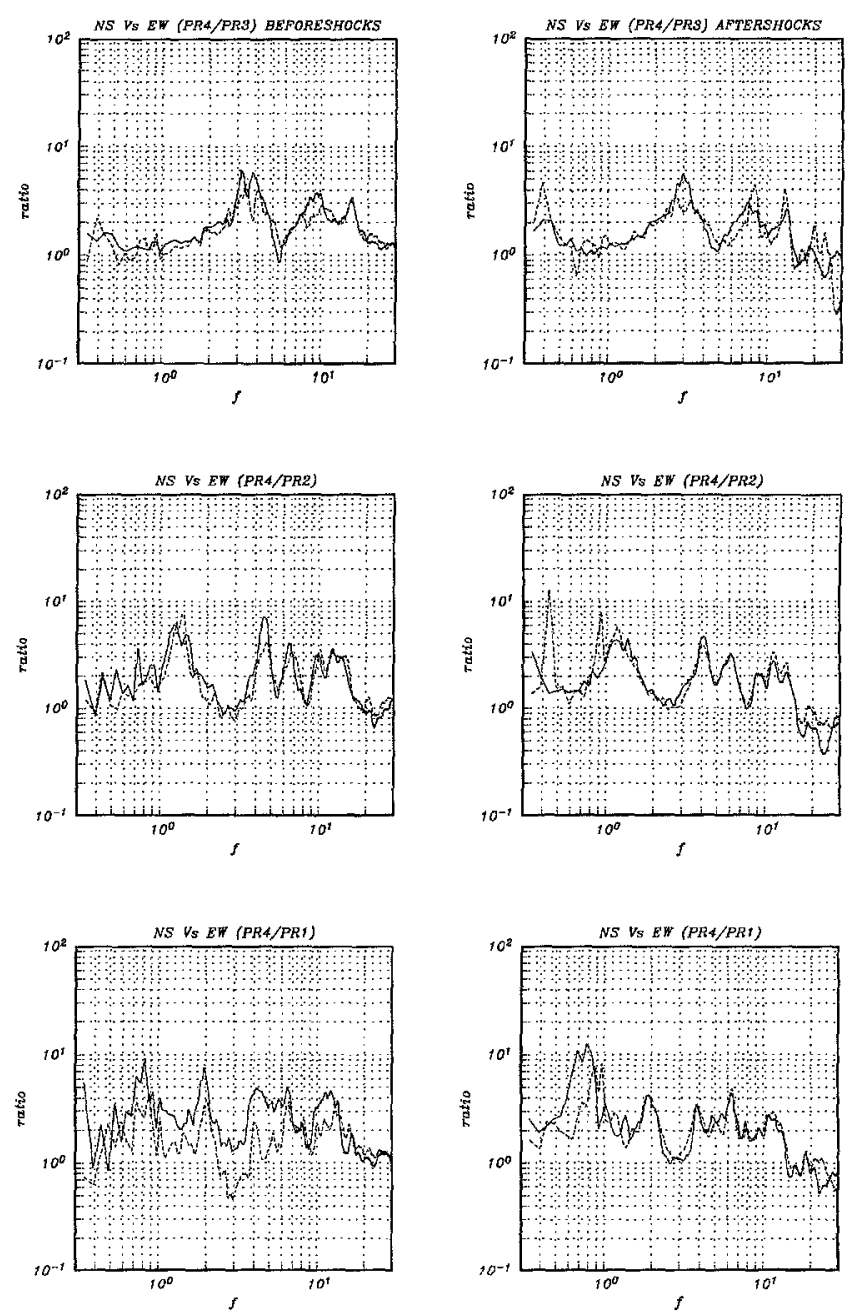

Figure 4. Spectral ratios, from top to bottom PR4/ PR3, PR4/PR2, and PR4/PR1: left, events before the mainshock, and right, events after the mainshock. The continuous line is for the E-W component, and the dashed line is for the N-S component.

using the records of only two remaining events. Even though the number of events used for calculation of the transfer function PR4/PR3 for the N-S component is very small in comparison with the number of events used for the $\mathrm{E}-\mathrm{W}$ component, both transfer functions are very similar to each other.

The averaged spectral ratios accurately represent the transfer function for the frequency band in which the standard deviation is small. For instance, the standard deviation for the ratios PR4/PR3 is large at frequencies smaller than $1 \mathrm{~Hz}$ and larger than $20 \mathrm{~Hz}$.

Comparing the transfer functions obtained from the events before the mainshock to the transfer functions from the aftershocks in the reliable frequency band (see Fig. 4), we found some differences; the peak spectral amplitudes before and after the mainshock are located at different frequencies. The change of the averaged ratios is clearer for PR4/PR3 than that for the rest, PR4/PR2 and PR4/PR1. The 
peak frequencies for the averaged ratios before the mainshock for the E-W component are 3.2, 3.7, 9.5, and 15.3 $\mathrm{Hz}$, while the peak frequencies for the averaged ratios after the mainshock are $2.9,7.4$, and $12.8 \mathrm{~Hz}$. All the peaks seem to shift to lower frequencies (about 20\%) for the aftershocks compared with the peaks for events observed before the mainshock. For the same component, the peak frequencies for the ratios PR4/PR2 are 1.2, 4.5, 6.5, 10.0, and $12.3 \mathrm{~Hz}$ for the events before the mainshock, and 1.2, 4.1, 6.1, and $11.3 \mathrm{~Hz}$ for the aftershocks. The reduction of the lowest peak frequency is about $5 \%$, smaller than the PR4/PR3 reduction. The averaged ratios PR4/PR1 for the same E-W component show the peaks at 2.0,4.2, 6.5, 8.0,11.4, 12.3, and $16.6 \mathrm{~Hz}$ for the events before the mainshock, and 1.9, 3.9, 5.5, 6.3, 9.5 , and $11.0 \mathrm{~Hz}$ for the aftershocks. The reduction of the lowest peak frequency for this case is also about $5 \%$. Since these peaks are closely related with the velocity and thickness of the layers, we will try to invert the appropriate parameters that explain the change of peak frequencies for the transfer functions before and after the mainshock.

Another interesting exploration is done in order to see the spectral ratio variation in the course of the $360 \mathrm{sec}$ during the mainshock and subsequent aftershocks (sections $\mathrm{A}$ to $\mathrm{H}$ in Fig. 2). We compute the spectral ratios for 11 events including the mainshock and aftershocks successively happening as shown by solid curves in Figure 5. The first two ratios, M-pI and M-pII, are for the beginning part of the $S$ waves of the mainshock record before liquefaction, and the part of $S$ waves after liquefaction. The 3 rd to 10 th correspond to the A to $\mathrm{H}$ events. The 11th is an aftershock about $3 \mathrm{hr}$ after the mainshock (exactly 8:58, 17 January 1995). For reference, the broken curves in Figure 5 show the averaged spectral ratios for the events before the mainshock and its standard deviation. The variation of the spectral ratios after the mainshock with respect to the pattern given from the events before the mainshock is dramatic for the ratios PR4/PR3 in the horizontal components. The records of the A to $\mathrm{H}$ events are mixed by the later phases from the mainshock and the aftershocks just after the mainshock. Nevertheless, we can see the variations of peak frequencies caused by the rigidity change of soil layers. For the vertical component, the difference from the reference transfer function is relatively small for the beginning part of the mainshock before the liquefaction took place and for the 17 January, 8:58 aftershock.

The ratio for the 17 January, 8:58 aftershock for the $\mathrm{N}$ $S$ component exhibits an extremely unusual amplification at low frequencies. The $\mathrm{N}-\mathrm{S}$ component acceleration record for this event, recorded at $-16 \mathrm{~m}$ itself, has very large amplitudes and looks strange compared with the other component and the deeper stations. It is very probable that during the recording of this earthquake the sensor enters in the malfunctioned status mentioned before. Therefore, the amplification observed in the $\mathrm{N}-\mathrm{S}$ component at low frequencies is related with an instrumental error.

From the time variation of the spectral ratios in Figure
5, we can see the physical properties changing due to liquefaction and gradually recovering with the lapse time.

Note that this variation after liquefaction is independent of the size of the peak acceleration. The variation in the horizontal components is larger than that in the vertical component. That is expected since the horizontal components include mainly $S$ waves that depend on $\mu$ (shear modulus), and the vertical component includes mainly $P$ waves that depend on a combination of $\mu$ and $\lambda$ (Lamé constants). We consider that the shear moduli of the liquefied layers between the surface and $16 \mathrm{~m}$ depth are reduced, close to zero ( $\mu=0$ for liquid), while $\lambda$ may not be changed.

\section{Inversion by Genetic Algorithms}

Since the transfer function for a given number of horizontal stratified layers is a nonlinear function of the velocity, thickness, and damping of each layer, the inversion of the velocities is a nontrivial problem even for the idealized case of vertical incidence of $S H$ waves. Here, we solve the problem with the help of genetic algorithms, assuming the vertical incidence of mainly $S H$ waves because the horizontal $\mathrm{N}-\mathrm{S}$ and $\mathrm{E}-\mathrm{W}$ components have almost the same tendencies. The transfer functions are simulated using a revised version of the Haskell-Thompson method where the damping was introduced (Silva, 1976). We assume a constant thickness of each layer, according to the original data (Development Bureau, Kobe City, 1991) based on the boring data. The averaged spectral ratios of the events occurring before the mainshock, the mainshock (divided into two parts before and after liquefaction), the $D$ event in Figure 2, and the aftershocks are selected to be used to invert the velocity structure by this method for the $S$ waves. Only the $D$ event among the A to $\mathrm{H}$ events has amplitude levels large enough compared with later phases of the mainshock.

For the first generation, several (a given number of individuals per generation) different models are proposed. Each model or individual has chromosomes chosen from the allowed space randomly. The theoretical transfer functions computed using the proposed models are compared in turn with the ratios PR4/PR3, PR4/PR2, and PR4/PR1. The per formance of each proposed model is judged by the normalized residual. The judgment is used by GA as the parameter to be minimized, and it determines the probability of reproduction, that is, survival, for the next generation. The individuals to produce the next generation are selected based on such probability of reproduction. The selected individuals interchange chromosomes in pairs, producing the new generation. The mutation is considered in order to avoid the tendency to obtain local minimum models. In the mutation, all the chromosomes have the mutation probability (in our case, 0.001 ) to be replaced by other randomly selected. $\mathrm{Ob}$ viously, the better individuals will remain through the generations. So, after several generations, the population is improved, and the performance of the better individuals are better. The goal of producing several generations with sev- 

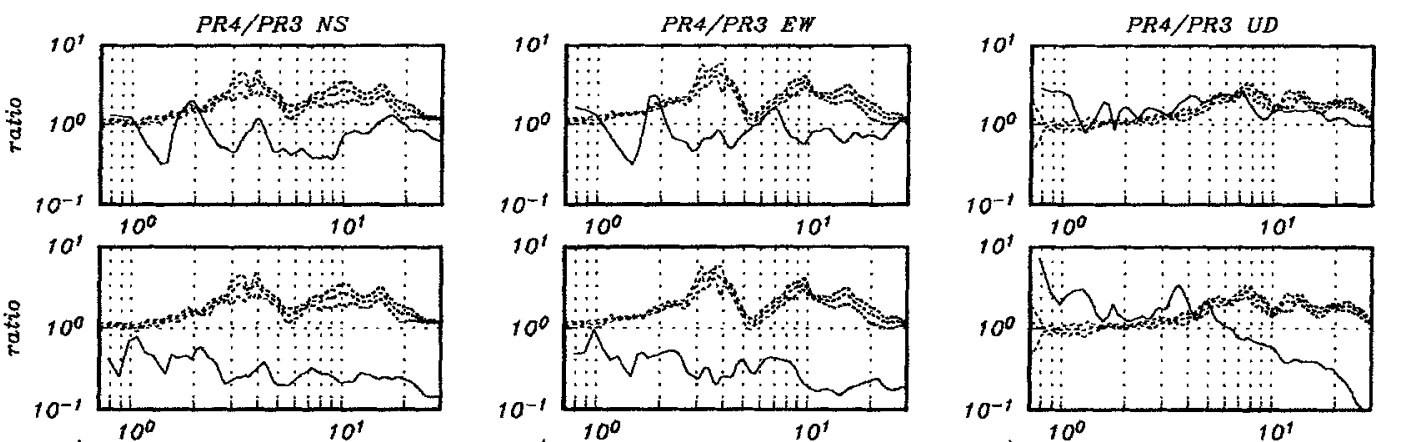

$M p I$
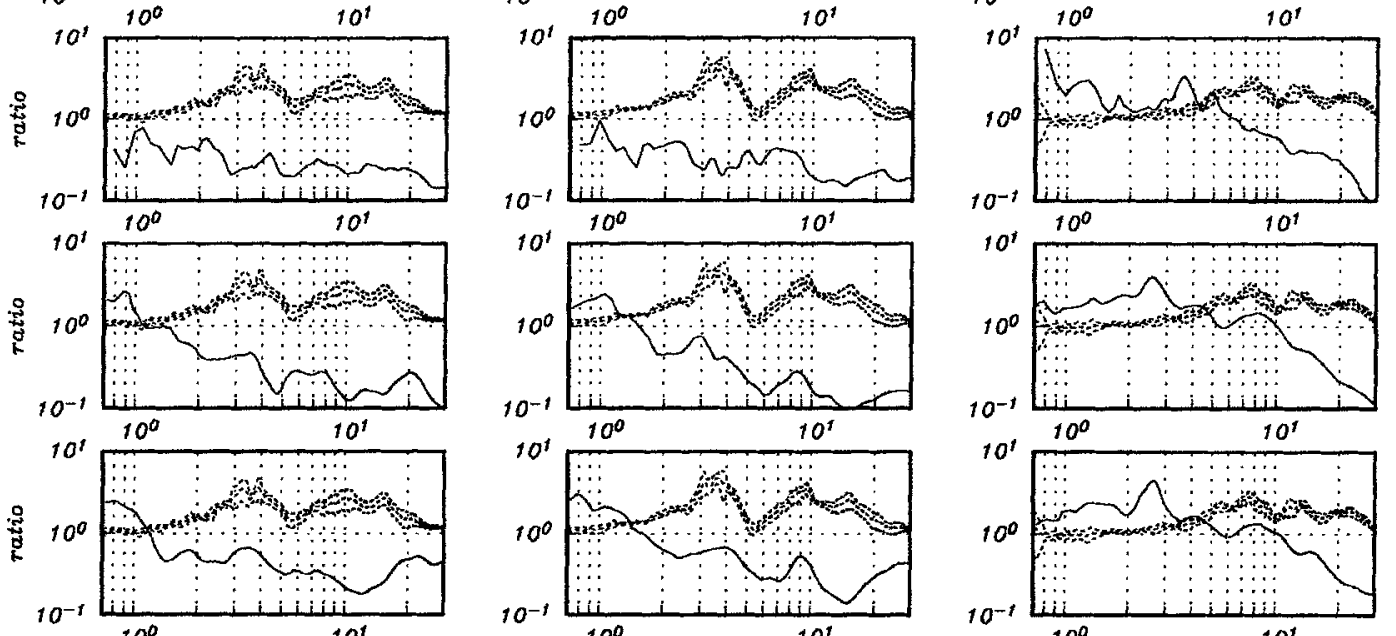

$M p I I$
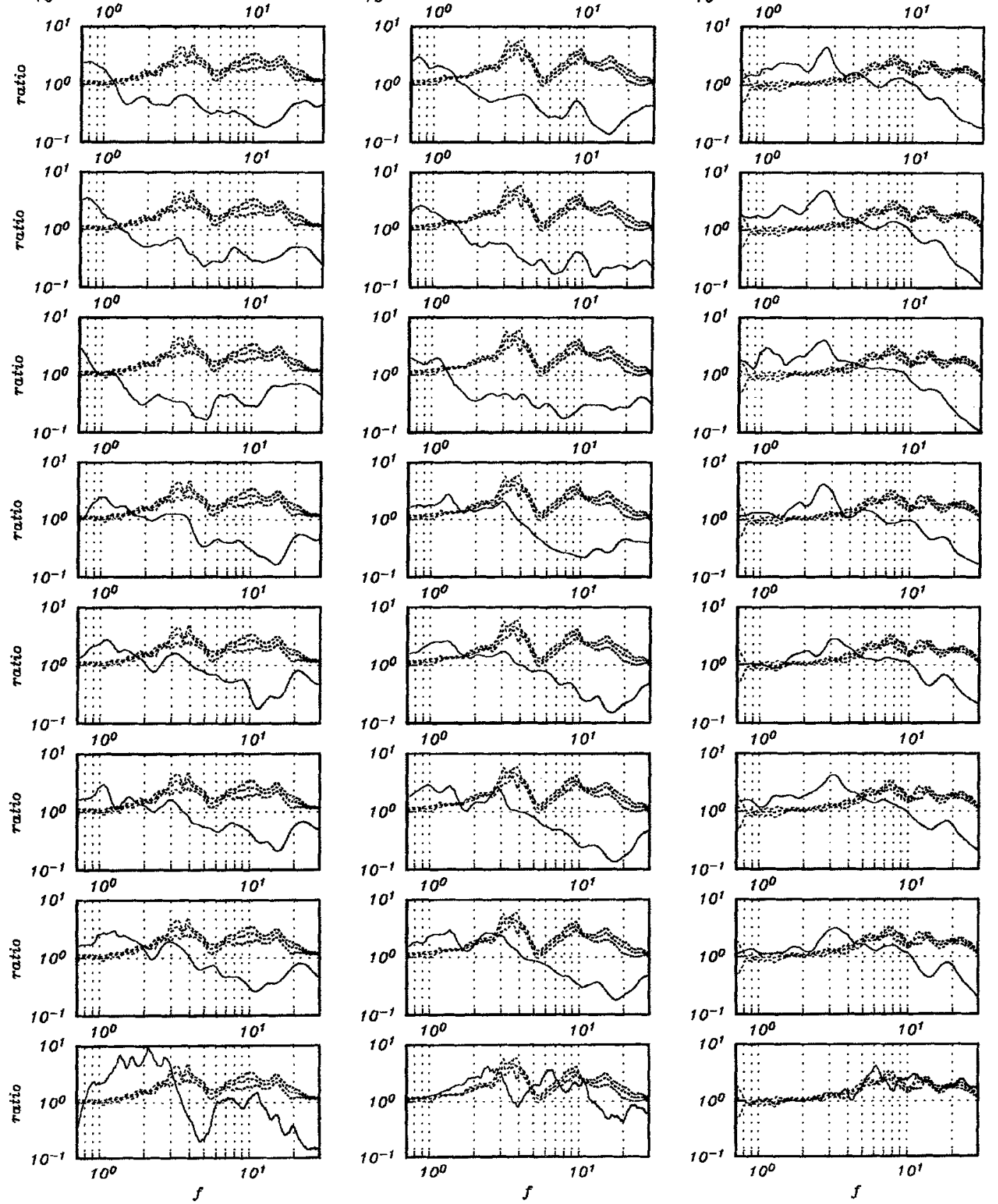

$B$

C

$D$
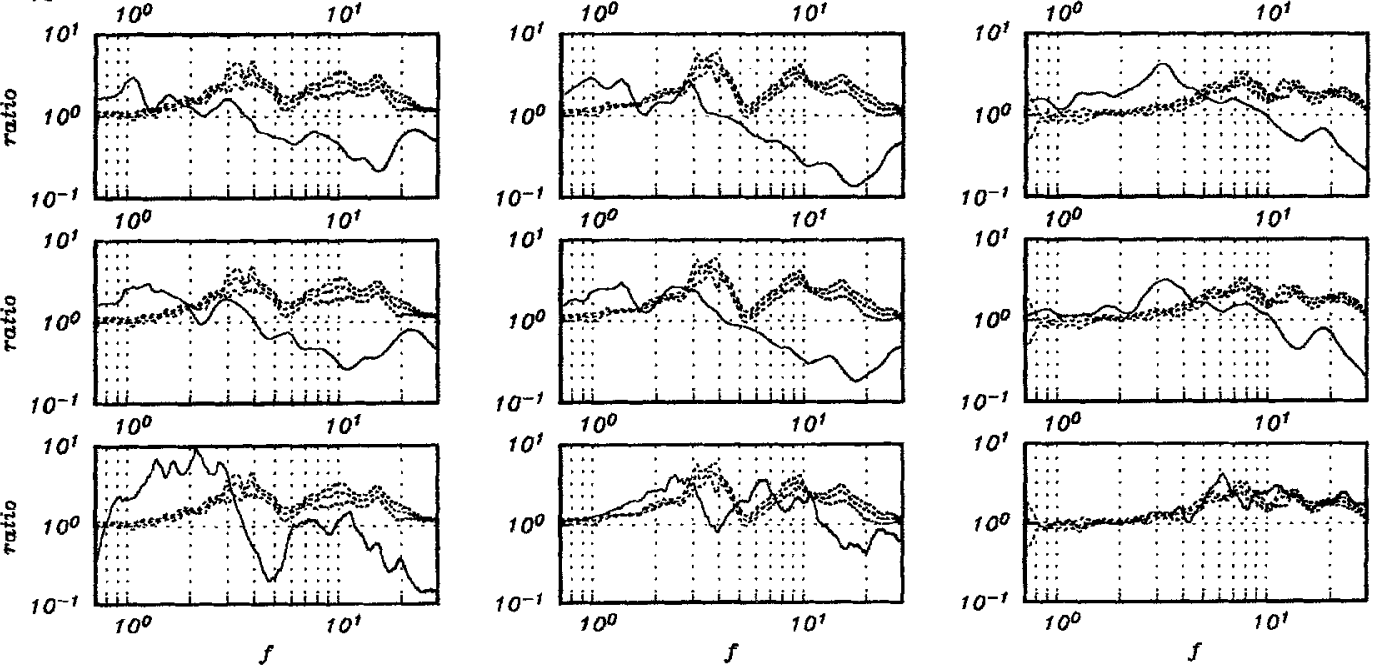

Jan. 17

$8: 58$ 
Figure 5. Variation of spectral ratios for different sections (in continuous line) with respect to the reference averaged spectral ratios before the mainshock and their standard deviation (dashed lines). Shown at left, the N-S component, E-W in the center, and UD in the right. From top to bottom, M-pI (mainshock before liquefaction), M-pII (mainshock after liquefaction), sections $A$ to $H$ (see Fig. 2), and 17 January, 8:58 aftershock.

eral individuals is to find the best individual that is the solution of the inversion. After several trials, we conclude that the population of 24 individuals and 52 generations produces an appropriate performance of the algorithm. In Figure 6, an example of the performance of GA for one of the aftershocks is shown. In this example, the population per generation is 24 , and the total number of generations is 52 , totally, 1248 individuals. One individual corresponds to one simulation. The genes of each individual for our case are the velocities and damping coefficients for each layer. To avoid problems of solutions, physically unreasonable searching space was limited. The lower velocity limit permitted for each layer is $5 \mathrm{~m} / \mathrm{sec}$, and the upper limit is $500 \mathrm{~m} / \mathrm{sec}$. In this way, the range of velocities is wide enough to allow slower or faster velocities than the originals, but within a physically reasonable band.

There are several possibilities to solve the problem. We compromise all the information for the four stations with different modalities. One of them was inverting the velocities and damping factors using the three spectral ratios separately and then interconnecting the results for common layers. The nonuniqueness of the solution in this kind of

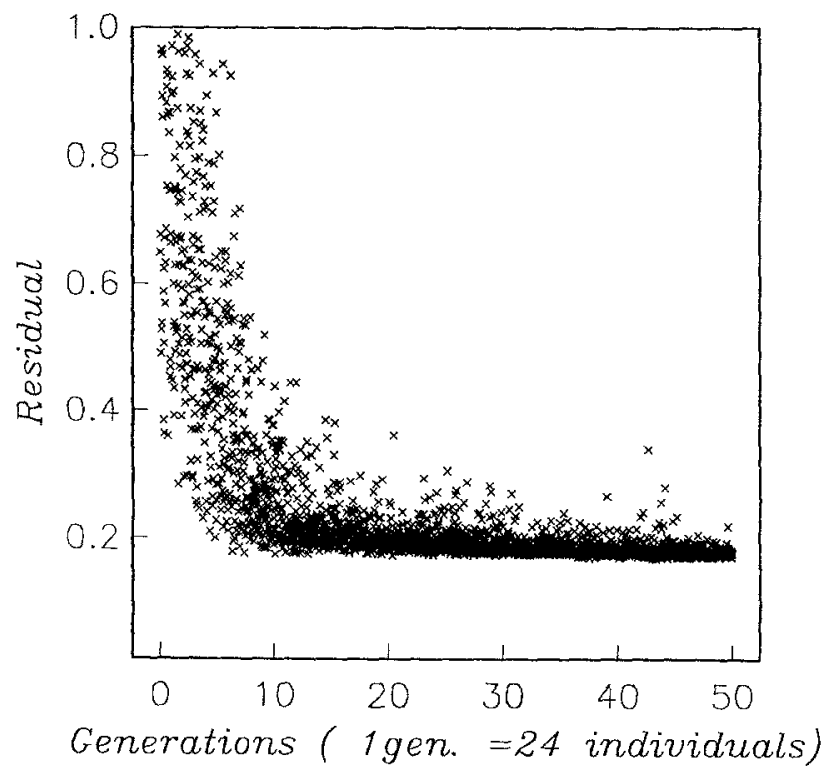

Figure 6. Example of the performance of genetic algorithms with 24 individuals per generation and 52 generations. problem produces a large dispersion when common layer characteristics obtained from different ratios were compared. Other modality consists in minimizing simultaneously the three spectral ratios PR4/PR3, PR4/PR2, and PR4/PR1. In this case, the result for each layer was unique, but due to the strict criterion, the approximation was poor and the residuals large. Also, we tried to invert interactively velocities with damping fixed and vice versa. This modality requires an initial model either for damping or for velocities; therefore, the result is strongly influenced by the initial model selected. The modality that gives us the best results is to invert the total structures by parts. We first invert the velocities and damping factors for 0 to $16 \mathrm{~m}$ depth, next for 16 to $32 \mathrm{~m}$ depth, and finally for 32 to $83 \mathrm{~m}$ depth using the ratios PR4/ PR3, PR4/PR2, and PR4/PR1, respectively.

For the inversion of the velocities before and after the mainshock, the E-W and N-S components are treated independently. First, the velocities and damping factors for the layers between 0 and $16 \mathrm{~m}$ were inverted based on the PR4/ PR3 averaged ratios. Next, using the velocities and damping factors obtained previously and the average ratios PR4/PR2, we invert the velocities and damping factors for the interval 16 to $32 \mathrm{~m}$ depth. Finally, the velocities between 32 and 83 $m$ depth were inverted using the ratio PR4/PR1, and the velocities and damping factors obtained in the two previous inversions for the layers from 0 to $32 \mathrm{~m}$ depth. The inverted velocities for the whole structure are shown in Figures 7 and 9. We compare the spectral ratios synthesized using the best models with the corresponding averaged spectral ratios be-

Vs for EW component

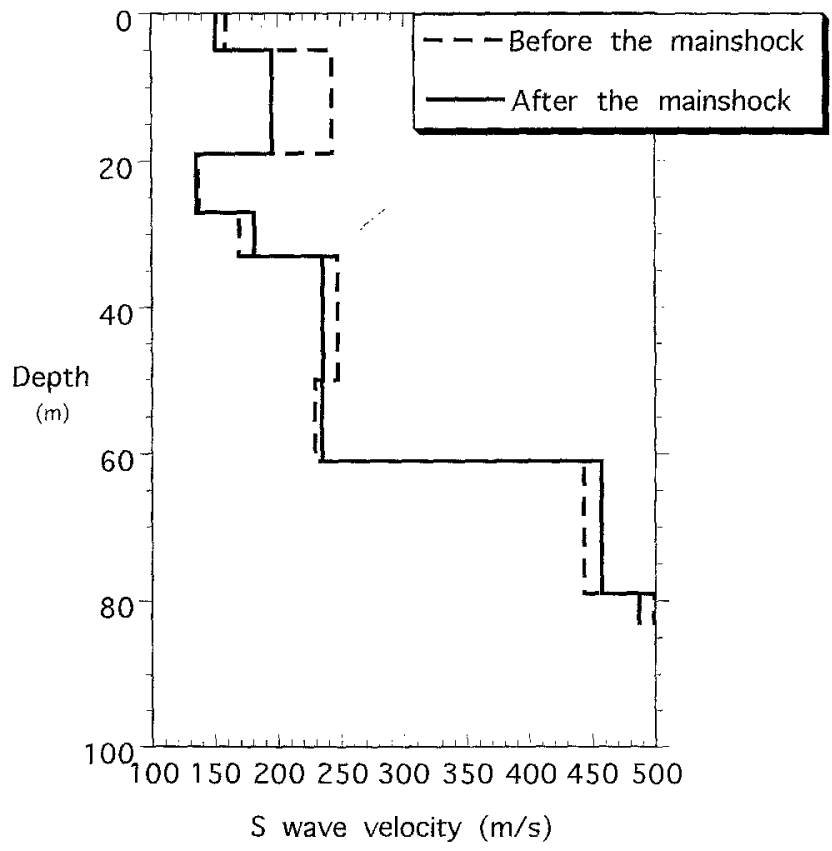

Figure 7. $S$-wave velocity structure inverted from the events before the mainshock and from the events after the mainshock, E-W component. 

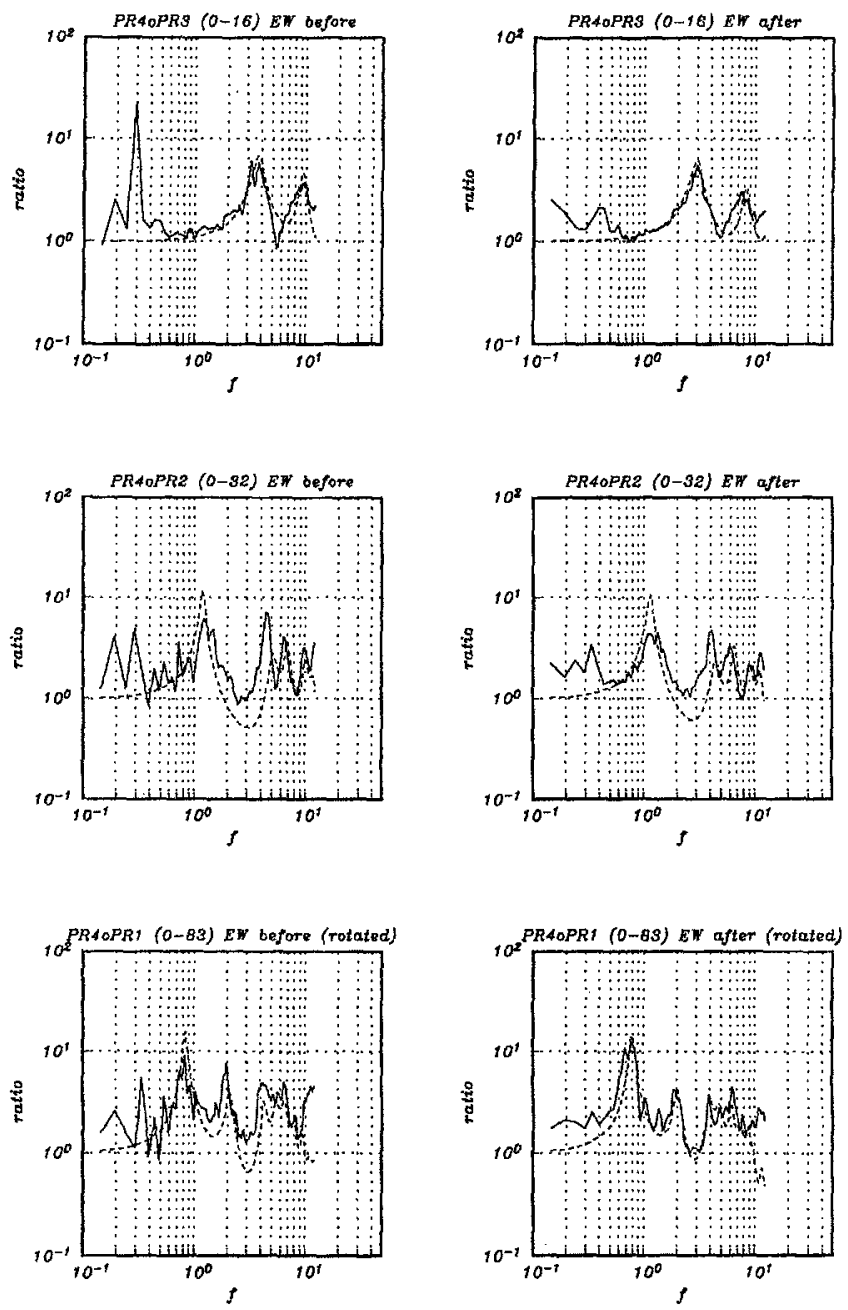

Figure 8. Observed spectral ratios (continuous line) compared with the synthesized spectral ratios (dashed line) using the result of the inversion in Figure 7 , for the $\mathrm{E}-\mathrm{W}$ component.

fore and after the mainshock, for $\mathrm{E}-\mathrm{W}$ and $\mathrm{N}-\mathrm{S}$ components separately in Figures 8 and 10. In Figures 11 and 12, the simulation of the $\mathrm{E}-\mathrm{W}$ horizontal motion for an event before the mainshock and for an aftershock using the corresponding results of the inversion are compared with the observation, respectively. In Tables 3 and 4, the results of the inversions are summarized.

The inversion for the aftershocks produces smaller residuals than the residuals for the events before the mainshock. Using a larger number of layers, this problem may be reduced, but as the number of parameters increases, the diversity of solutions for the same spectral ratio increases also.

For interpreting Figures 7 and 9, we should consider that the velocities inverted from the observed data at near surface are better controlled than those at deeper. It is easy to note since the information about the surficial layers ( 0 to $16 \mathrm{~m}$ depth) is included in all three spectral ratios (PR4/PR3, PR4/PR2, and PR4/PR1), about the intermediate layers (16
Vs for NS component

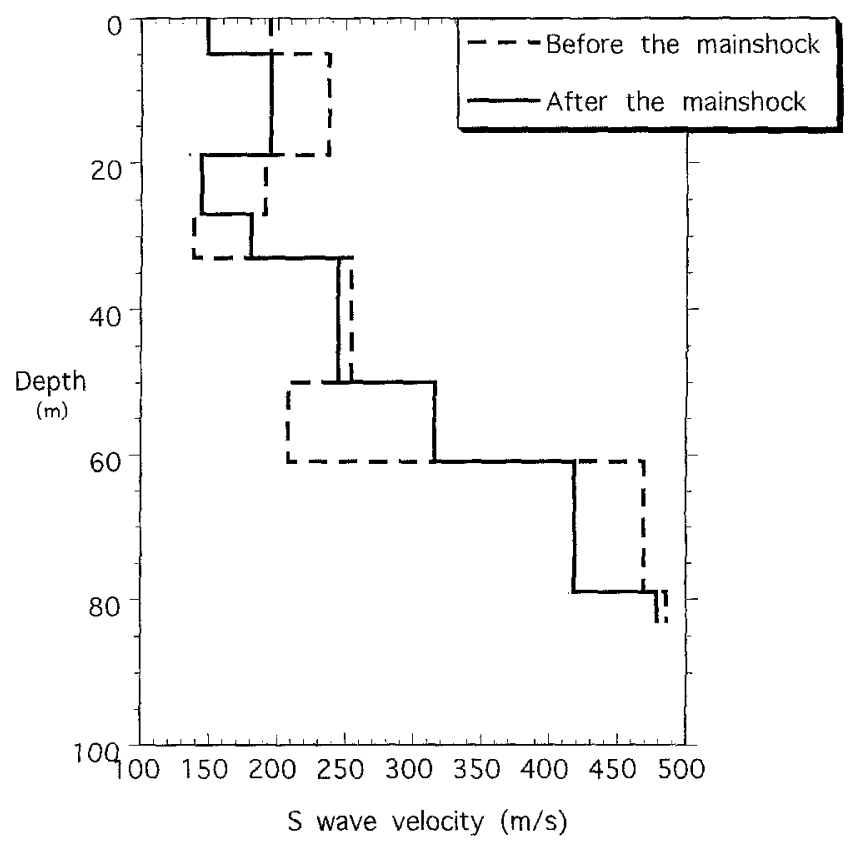

Figure 9. $S$-wave velocity structure inverted from the events before and after the mainshock, N-S component.

to $32 \mathrm{~m}$ depth) in two spectral ratios (PR4/PR2 and PR4/ PR1), and about the deeper layers ( 32 to $83 \mathrm{~m}$ depth) in only one ratio (PR4/PR1). Then, the lack of resolution produces the dispersion observed from one to another inversion in the deeper layers, for instance, layers 50 to $61 \mathrm{~m}$ depth and 61 to $79 \mathrm{~m}$ depth. The velocities inverted for the two layers located between 19 and $33 \mathrm{~m}$ depth from the events before mainshock for component N-S seems to be affected by the nonuniqueness of solutions. The inversion for the $\mathrm{E}-\mathrm{W}$ component gives a better result with smaller residuals than that for the N-S component. The layer 5 to $16 \mathrm{~m}$ depth is the only one that shows a clear and systematic difference between the models before and after the mainshock in this analysis. Since this layer is close to the surface, the parameters are well controlled. Linking these results with other observational facts, it is possible to find a physical interpretation, as is discussed later. During the strong ground motions, the $S$-wave velocity is not a constant but is dependent on the level of strain, as expected from a nonlinear relationship. But it is possible to obtain an approximation using a constant velocity considering the concept of "equivalent linear" introduced by Idriss and Seed (1968).

In the case of the mainshock, the inversion is divided into two parts: $\mathrm{pI}$ and pII. The division is to consider apparent velocities before and after the liquefaction occurrence. The liquefaction is assumed to start $15.3 \mathrm{sec}$ after the beginning of the record (Report of the Japanese Society of Soil Mechanics, 1996). The $S$-wave velocities are found to be smaller just after the liquefaction occurs and later tend to 

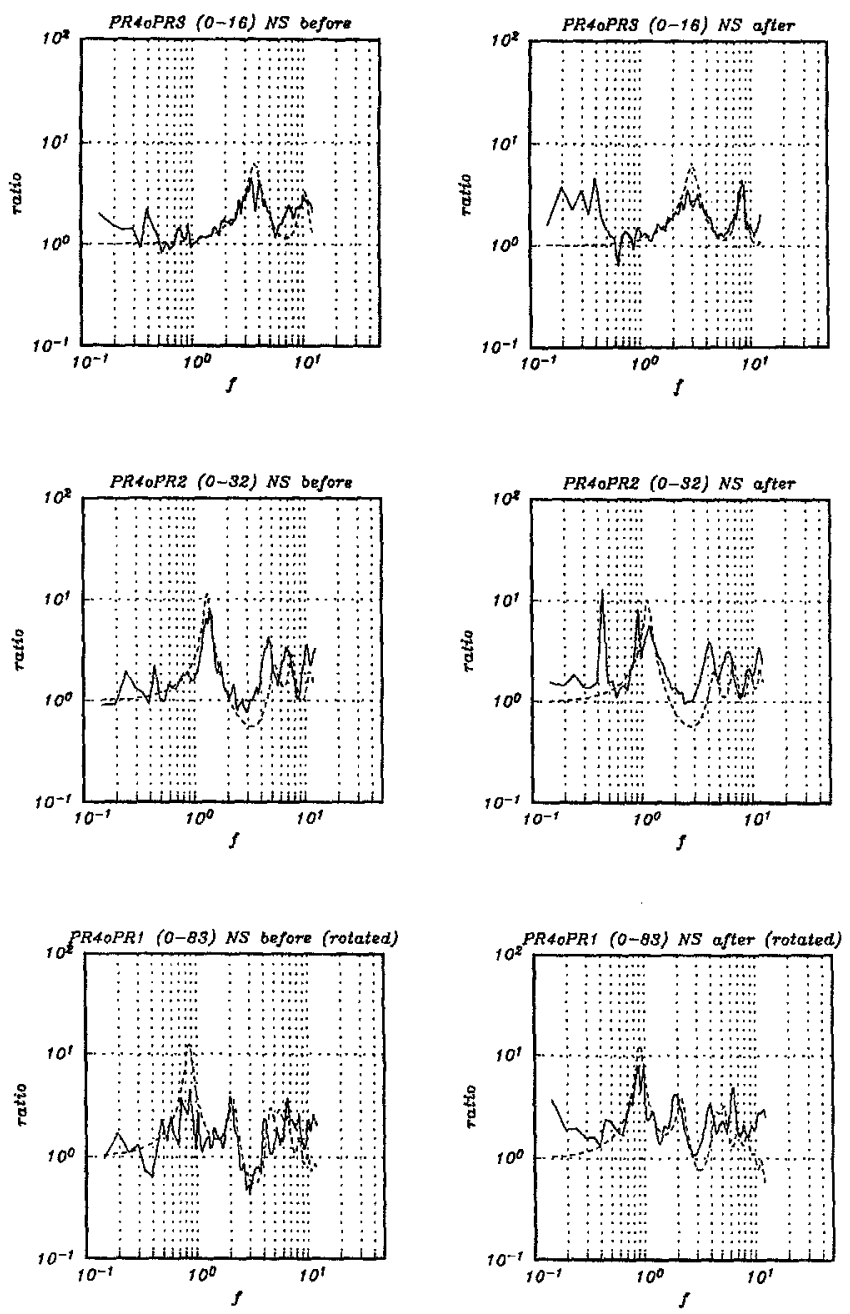

Figure 10. Observed spectral ratios (continuous line) compared with the synthesized spectral ratios (dashed line) using the result of the inversion in Figure 9 , for the N-S component.

increase gradually, as was verified with the inversions of the velocities for the subsequent aftershocks $D$ and the 17 January, 8:58 aftershock occurring $3 \mathrm{hr}$ after the mainshock shown in Figure 13. Even though the level of accelerations recorded during this time at the surface were small enough to be considered as a linear response, the spectral ratio analysis shows the nonlinear character of the response. That is the permanence in the liquefaction state.

After the mainshock, normal ground motions had not been recorded until the 18 January 1995, 5:40 aftershock about $24 \mathrm{hr}$ after the mainshock. After this time, the response of the layers in the linear range can be predicted by the velocity structure model obtained previously for the aftershocks.

\section{Nonlinear Simulation}

We perform the simulation of the 1995 Hyogo-ken Nanbu earthquake including the nonlinear characteristics of
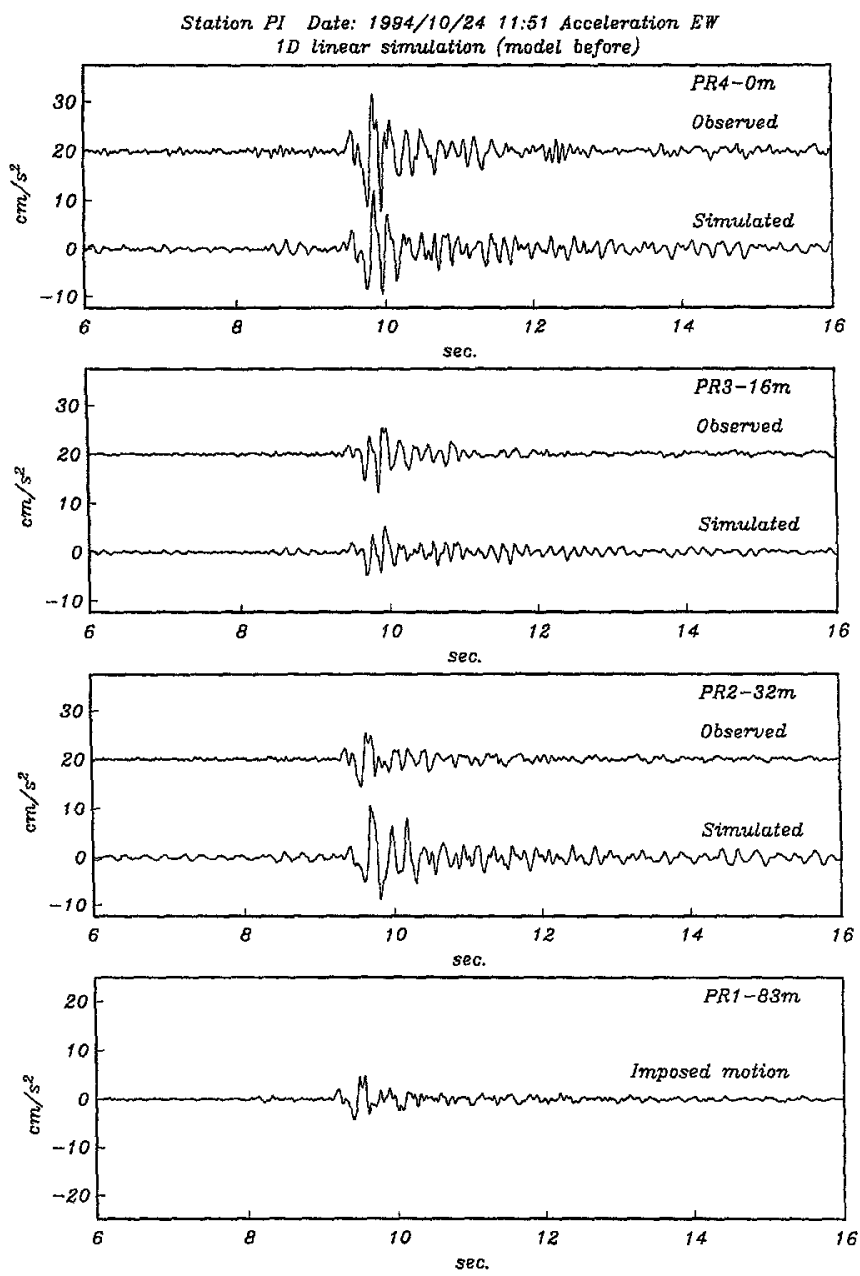

Figure 11. Simulation of acceleration waveforms (E-W component) for the event occurring at 11:51 hr on 24 October 1994 using the velocity structure model inverted from the events before the mainshock (see Fig. 7).

the soil based on the velocity structure obtained for the events before the mainshock. This simulation was carried out by the same program as Perez-Rocha and SanchezSesma (1992), which is a revised version of the Joyner and Chen (1975) original program. The nonlinearity is modeled by a Hardin and Drnevich (1972) model curve. The convenience of using this model is that the nonlinearity depends basically on one parameter, the failure strength. The nonlinearity is normalized by the failure strength depending on the properties of the layer and its position. The layers are represented as a discrete medium in which the stress and displacement are computed carrying out the time integration step by step using the finite-difference technique. In this way, the nonlinear stress-strain relation can be introduced appropriately. Joyner and Chen (1975) presented a detailed explanation of the method.

The velocities, densities, and failure strength for each layer used for the simulation are in Table 5. We use the parameters obtained by the inversion from the events before 

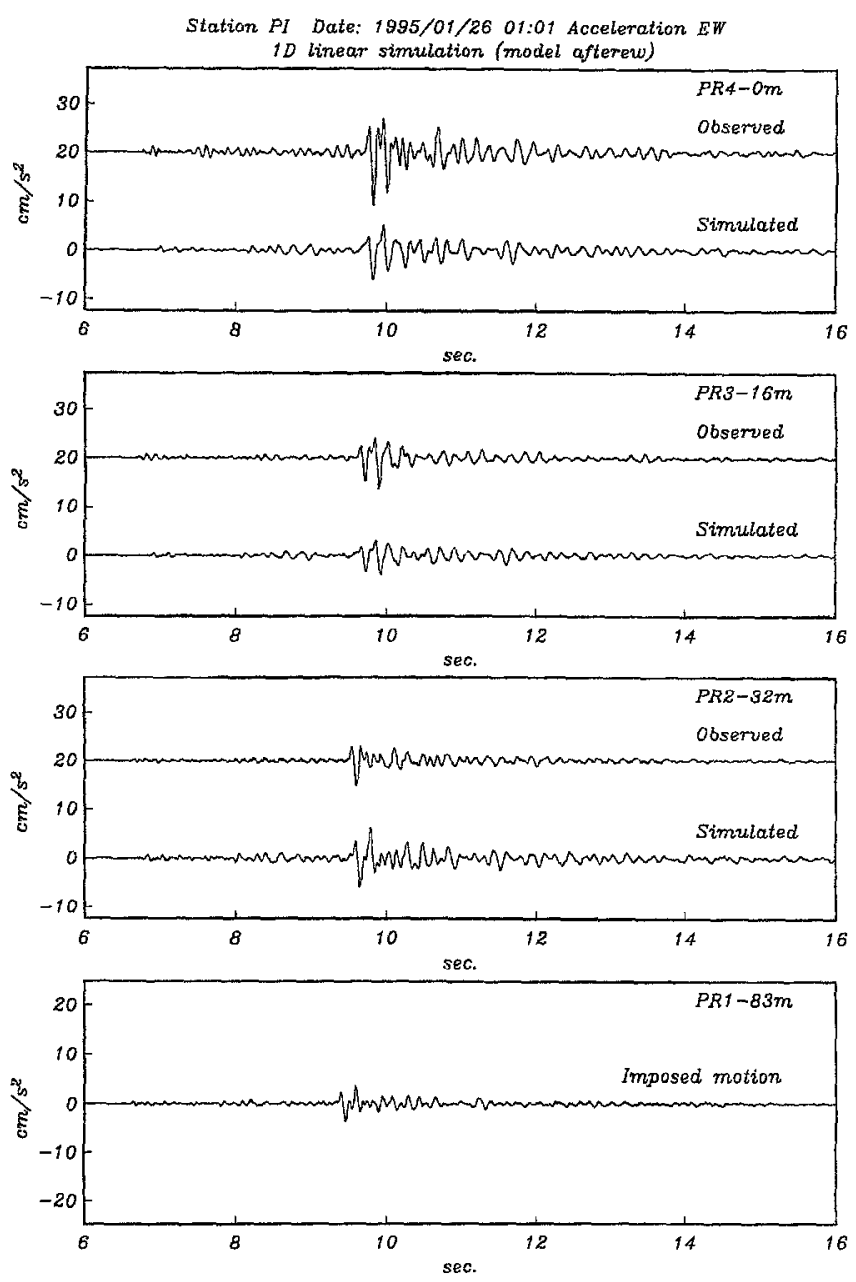

Figure 12. Simulation of acceleration waveforms (E-W component) for the event occurring at 01:01 hr on 26 January 1995 using the velocity structure model inverted from the events after the mainshock (see Fig. 7).

Table 3

Result of the Inversion of $S$-Wave Velocities and Damping (Velocities shown here)

\begin{tabular}{ccccc}
\hline Layer & $V_{S}$ before $\mathrm{N}-\mathrm{S}$ & $V_{S}$ before $\mathrm{E}-\mathrm{W}$ & $V_{S}$ after N-S & $V_{S}$ after $\mathrm{E}-\mathrm{W}$ \\
\hline $0-5.0$ & 194.0 & 159.0 & 149.0 & 151.0 \\
$5.0-19.0$ & 237.0 & 244.0 & 195.0 & 196.0 \\
$19.0-27.0$ & 191.0 & 137.0 & 144.0 & 136.0 \\
$27.0-33.0$ & 138.0 & 169.0 & 180.0 & 182.0 \\
$33.0-50.0$ & 254.0 & 248.0 & 244.0 & 236.0 \\
$50.0-61.0$ & 208.0 & 230.0 & 315.0 & 235.0 \\
$61.0-79.0$ & 469.0 & 443.0 & 418.0 & 457.0 \\
$79.0-(83.0)$ & 486.0 & 499.0 & 478.0 & 487.0 \\
\hline
\end{tabular}

the mainshock, and the failure strengths were estimated following Iwasaki (1987). We synthesize the acceleration waveforms including the nonlinearity at 32,16 , and $0 \mathrm{~m}$ depth imposing the observed motion at $83 \mathrm{~m}$. In Figures 14 and 15 , the results of the simulation are compared with the observed acceleration records.
Table 4

Result of the Inversion of $S$-Wave Velocities and Damping (Damping shown here)

\begin{tabular}{ccccc}
\hline Layer & $h_{s}$ before N-S & $h_{s}$ before E-W & $h_{s}$ after N-S & $h_{s}$ after E-W \\
\hline $0-5.0$ & 0.020 & 0.011 & 0.009 & 0.119 \\
$5.0-19.0$ & 0.115 & 0.115 & 0.115 & 0.066 \\
$19.0-27.0$ & 0.057 & 0.042 & 0.048 & 0.078 \\
$27.0-33.0$ & 0.009 & 0.011 & 0.005 & 0.005 \\
$33.0-50.0$ & 0.002 & 0.009 & 0.011 & 0.004 \\
$50.0-61.0$ & 0.105 & 0.029 & 0.028 & 0.003 \\
$61.0-79.0$ & 0.059 & 0.012 & 0.088 & 0.049 \\
$79.0-(83.0)$ & 0.005 & 0.048 & 0.012 & 0.049 \\
\hline
\end{tabular}

Generally speaking, the simulation fits well the whole observed records for the PR2 and PR3 stations. The simulation at the surface fits well the observed signal for the first $15 \mathrm{sec}$ of the observed records in Figures 14 and 15 before the liquefaction onset. The reason of the misfit after this time is that our simulations do not consider the water pressure development, and then it is not able to reproduce the effects of liquefaction. Nevertheless, it is helpful to estimate the peak acceleration and to identify the occurrence of liquefaction. Simulations including the water pressure development have been done by several authors, such as Sato et al. (1996), Yoshida et al. (1995), Cubrinovski and Ishihara (1996), and Elgamal et al. (1996).

\section{Discussion}

The horizontal acceleration records in Port Island by themselves show the influence of the nonlinearity during the 1995 Hyogo-ken Nanbu earthquake since the accelerations at the surface are reduced in comparison with the accelerations at deeper ground contrary to the amplification expected from linear theory. However, for the UD component, the nonlinearity is not significant before the liquefaction occurrence. Aguirre and Irikura (1995) showed that the observed acceleration for the $U D$ component is well approximated by the linear simulation in peak amplitude and general features. This conclusion is supported by the spectral ratios of Figure 5 in which the nonlinearity of the spectrum during the first part of the mainshock (before the liquefaction) for the $U D$ component is smaller than that for the horizontal components.

In the horizontal components, the variation of the averaged spectral ratios after the mainshock in comparison with the averaged spectral ratios before the mainshock evinces a change in the $S$-wave velocity of the layers. These changes related with the peak frequencies are larger for the averaged ratios PR4/PR3 than for those of PR4/PR2 and PR4/PR1. The change of the $S$-wave velocities in the surficial layers ( 0 to $16 \mathrm{~m}$ ) affects the peak frequencies of the ratios PR4/PR2 and PR4/PR1 because they are part of the layers between surface and $-32 \mathrm{~m}$ and between surface and $-83 \mathrm{~m}$. However, the effect of the surficial layers on the 
Vs for EW component

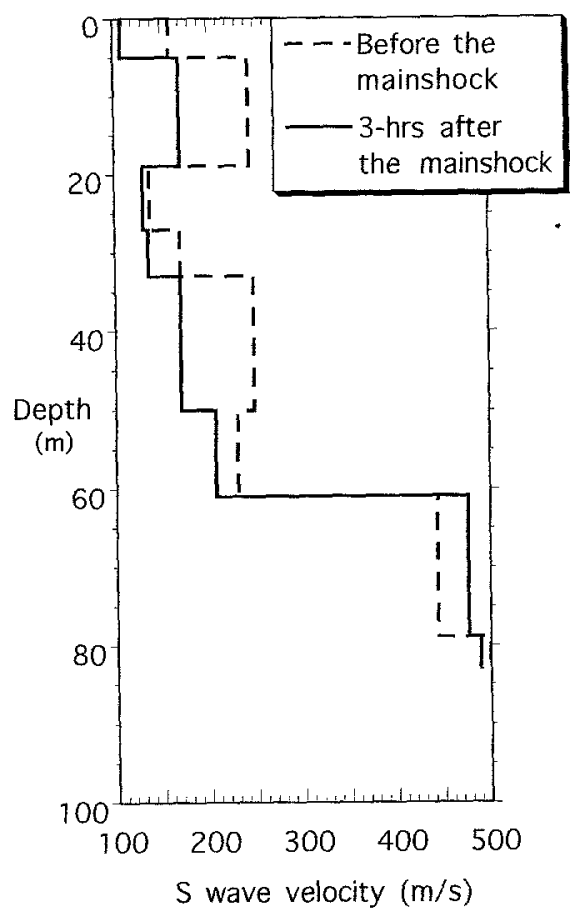

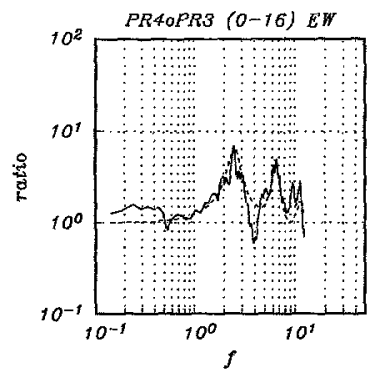
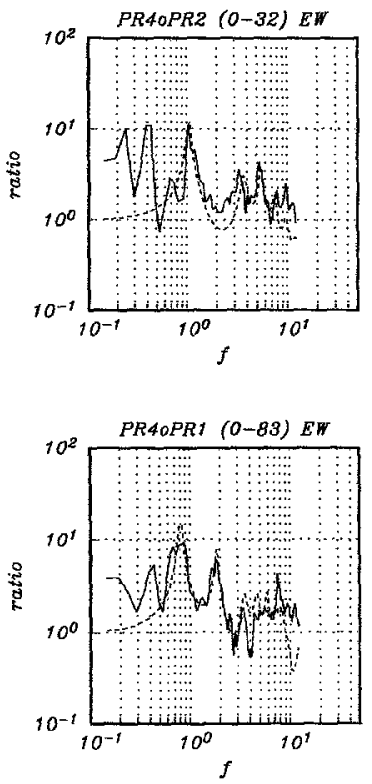

Figure 13. S-wave velocity structure inverted from the $8: 58 \mathrm{hr}, 17$ January 1995 event for the E-W component in the left, and comparison of observed spectral ratios (continuous line) with the simulated using the inverted velocity structure (dash line) in the right.
Table 5

Parameters Used for the Nonlinear Simulation

\begin{tabular}{ccccc}
\hline $\begin{array}{c}\text { Thickness } \\
(\mathrm{m})\end{array}$ & $\begin{array}{c}\text { Density } \\
\left(\text { ton }^{3} \mathrm{~m}^{3}\right)\end{array}$ & $\begin{array}{c}S \text {-wave Velocity } \\
(\mathrm{m} / \mathrm{sec})\end{array}$ & $\begin{array}{c}\text { Damping } \\
\text { Factor }\end{array}$ & $\begin{array}{c}\text { Failure Strength } \\
\left(\mathrm{dyn} / \mathrm{cm}^{2}\right)\end{array}$ \\
\hline 2.0 & 1.8 & 194.0 & 0.07 & $3.25 \mathrm{E} 06$ \\
3.0 & 1.8 & 194.0 & 0.07 & $5.15 \mathrm{E} 06$ \\
7.6 & 1.8 & 237.0 & 0.08 & $1.21 \mathrm{E} 07$ \\
3.4 & 1.8 & 237.0 & 0.08 & $1.37 \mathrm{E} 07$ \\
3.0 & 1.8 & 237.0 & 0.02 & $1.49 \mathrm{E07}$ \\
8.0 & 1.5 & 191.0 & 0.50 & $1.64 \mathrm{E} 07$ \\
5.0 & 1.85 & 138.0 & 0.50 & $6.62 \mathrm{E} 06$ \\
1.0 & 1.85 & 138.0 & 0.50 & $6.73 \mathrm{E} 05$ \\
17.0 & 1.85 & 254.0 & 0.50 & $2.84 \mathrm{E} 06$ \\
11.0 & 1.85 & 208.0 & 0.50 & $2.11 \mathrm{E} 06$ \\
18.0 & 1.80 & 469.0 & 0.50 & $11.87 \mathrm{E} 08$ \\
4.0 & 1.90 & 486.0 & 0.50 & $13.86 \mathrm{E} 08$ \\
\hline
\end{tabular}

peak frequencies is much smaller in the ratios PR4/PR2 and PR4/PR1 than in the ratios PR4/PR3. The inverted models of $S$-wave velocity for the 0 to $16 \mathrm{~m}$ depth interval obtained from the average spectral ratio (PR4/PR3) are well distinguished before the mainshock and after the mainshock, because of the clear variation of the peak frequencies in the those ratios, whereas the ratios PR4/PR1 before and after the mainshock do not resolve clearly the velocities for the deeper layers (from 16 to $83 \mathrm{~m}$ depth). However, there is no indication that the layers below $32 \mathrm{~m}$ depth had suffered liquefaction, and therefore, the possibility of large velocity changes in deeper layers $(>16 \mathrm{~m})$ is smaller than in the surficial layers $(<16 \mathrm{~m})$ affected by the liquefaction. In our analysis, only the second (5 to $16 \mathrm{~m}$ ) layer presents systematic change with a reduction of $20 \%$ of $S$-wave velocity. The nonlinear simulations of the acceleration waveforms performed here agrees satisfactorily with the observed accelerations, except for the ones at the surface after the liquefaction occurred. The misfit is natural since our simulations do not take into account the liquefaction. This result means that the zone of liquefaction occurrence is restricted to the layers shallower than $16 \mathrm{~m}$.

Once we fix the second layer ( 5 to $16 \mathrm{~m}$ depth) as the layer more affected by the liquefaction, let us discuss the temporal variation of the $S$-wave velocities for this layer. Actually, we know that there is a variation of the $S$-wave velocity before and after the mainshock caused by the liquefaction. From the linear equivalent velocities inverted from the $\mathrm{pI}$ and $\mathrm{pII}$ during the mainshock (before and after the liquefaction onset), the $D$ aftershock ( $3 \mathrm{~min}$ after the mainshock), and the 8:53 aftershock ( $3 \mathrm{hr}$ after the mainshock), we can observe a sharp reduction of the $S$-wave velocity just after the liquefaction onset and gradual recovery of the $S$-wave velocity for this second layer. This means that 
Station PRT Date: 1995/01/17 05:46 Accel. EW Comparison of observations and $1 D$ non-linear simulations.
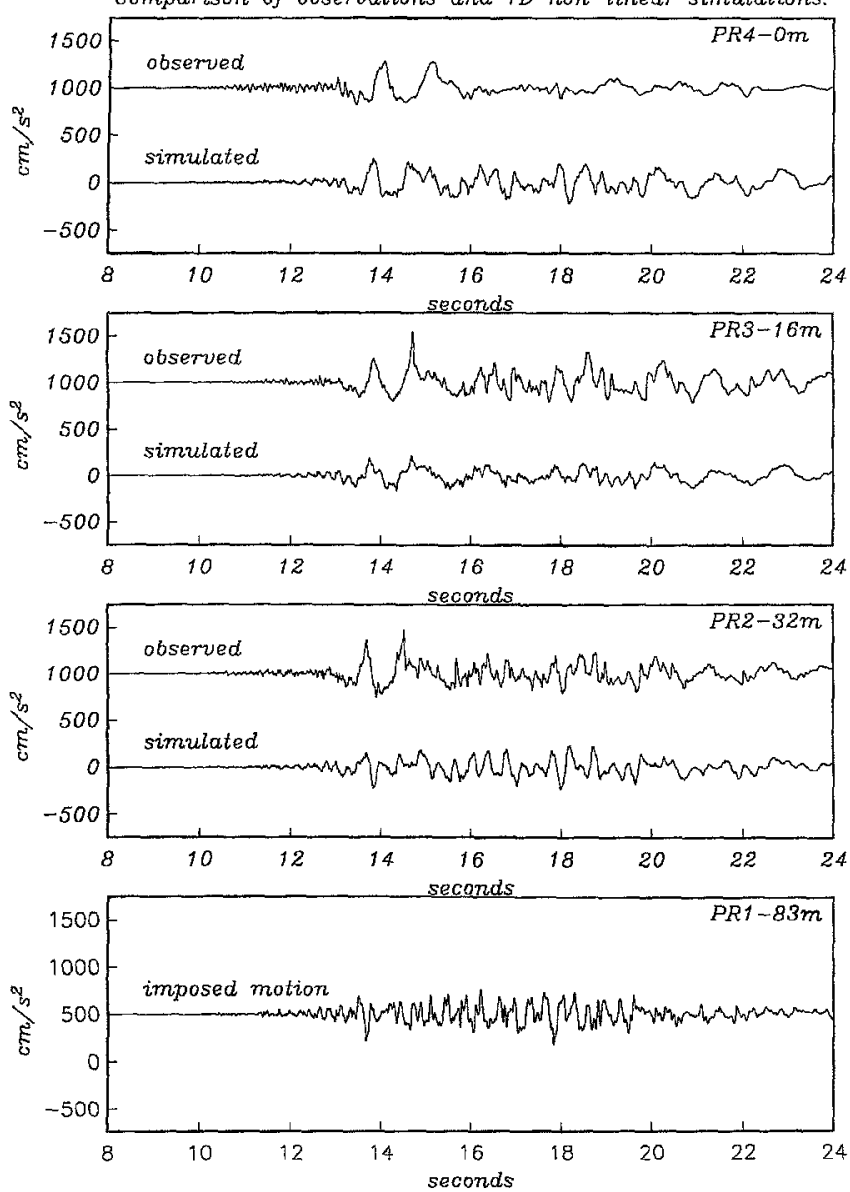

Figure 14. Nonlinear simulation for E-W components and the recorded accelerations in Port Island for the 1995 Hyogo-ken Nanbu earthquake using the parameters in Table 5.

the layer is completely liquefied, and the $S$-wave velocity is reduced to be close to zero; that result is in good agreement with the $S$-wave velocities obtained for the same interval by Sato et al. (1996) and Elgamal (1996). Later, the layer's $S$ wave velocity is increased gradually. We found that $3 \mathrm{hr}$ after the mainshock the recovery was not complete, but it was almost completed after $24 \mathrm{hr}$. Figure 16 shows the process schematically; note that the horizontal axis does not have a linear scale because the time is elongated and shrank for different intervals. Solving the differential equation for 1D (one dimension) consolidation model, Terzaghi (1956) showed that the percentage of consolidation $(U)$ has an exponential dependency with respect to the time $\{U=1-$ $\exp [-f(t)]\}$. Considering that the process after liquefaction involves consolidation, it is expected to follow the same tendency as the curve of consolidation shown by Terzaghi (1956).

Here we discuss the cause of $S$-wave velocity reduction in the second layer. After the liquefaction, settlement of the surficial layer ( $50 \mathrm{~cm}$ in average) has been reported on Port
Station PRT Date: 1995/01/17 05:46 Accel. NS
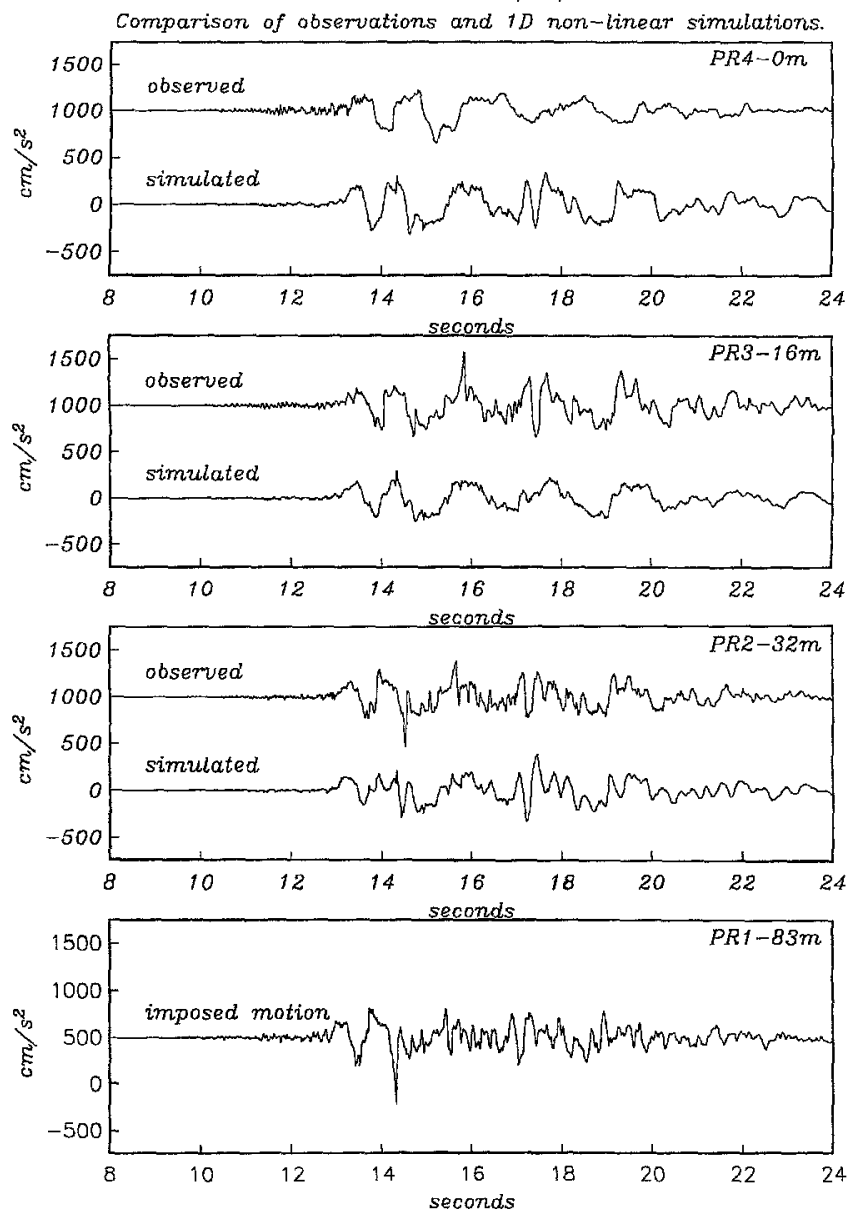

Figure 15. Nonlinear simulation for N-S component and the recorded accelerations in Port Island for the 1995 Hyogo-ken Nanbu earthquake using the parameters in Table 5.

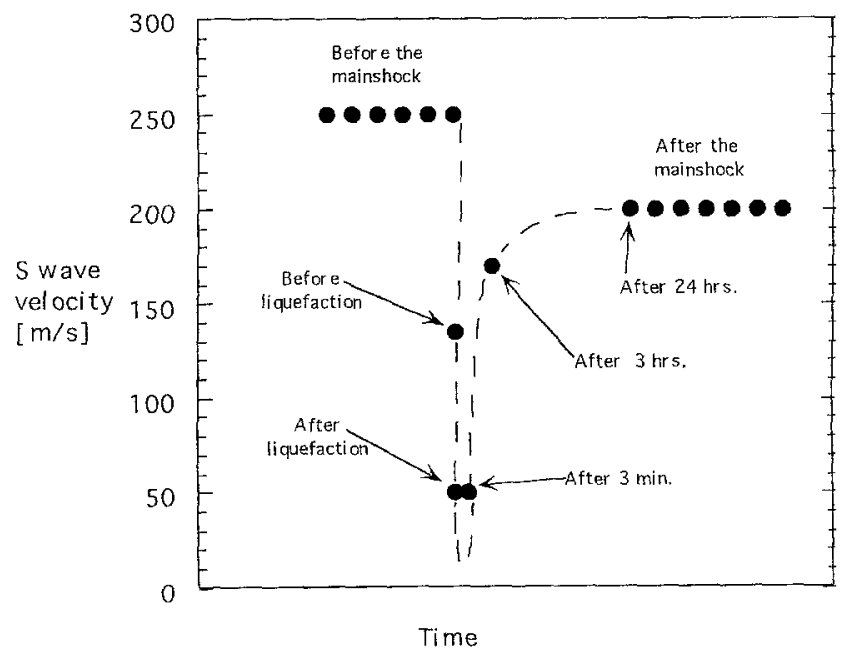

Figure 16. Schematic representation of the $S$ wave velocities in Port Island for the second layer (5 to $16 \mathrm{~m}$ ) before, during, and after the 1995 Hyogoken Nanbu earthquake. 
Island (Ishihara et al., 1996). That indicates that the density of the second layer increased after the liquefaction. On the other hand, we found in this article a reduction of shear wave velocity of $20 \%$. Also, the logging data show an $S$-wave velocity reduction of about $20 \%$ in average for the same layer (Development Bureau, Kobe City, 1995). A reduction of $S$-wave velocity in $20 \%$ indicates a density increase of $56 \%$, if we consider the $\mu$ constant. Considering the density before the mainshock as $1.8 \mathrm{~g} / \mathrm{cm}^{3}$, the increase of $56 \%$ is physically unreasonable. Then such a change in velocity only can be explained with a simultaneously increase of density and reduction of $\mu$.

The aftereffects of liquefaction remain at least about 3 hr after the mainshock, as can be seen in the nonlinear response during the 17 January, 08:58 aftershock. The liquefaction causes a permanent variation of the elastic properties of the liquefied layers. This implies that the seismic response at liquefied sites after the earthquake is different from before.

\section{Conclusions}

From the spectral analysis, we observed a large variation of the spectral ratios during the strong ground motions and during the liquefaction state (Fig. 5). The spectral ratios after the mainshock (and after the liquefaction state) are different from those before the mainshock. The peak frequencies in the spectral ratios after the mainshock are shifted to lower frequencies by about $20 \%, 5 \%$, and $5 \%$ in comparison to the spectral ratios before the mainshock for the PR4/PR3, PR4/PR2, and PR4/PR1, respectively.

The results of the $S$-wave velocity inversions showed clear differences between the velocity structures obtained before and after the mainshock; most notably, the $S$-wave velocity of the $2 \mathrm{nd}$ layer, from 5 to $16 \mathrm{~m}$ depth, after the mainshock was lower than before.

The biggest change of soil rigidity was observed several seconds after liquefaction occurrence, then it gradually recovered following an inverse exponential relation with time (as in the case of consolidation). After the recovery was completed, the $S$-wave velocity of the second layer (5 to 16 $m$ depth) was $20 \%$ lower than that before the mainshock. The other layers did not show a systematic variation.

The aftereffects of liquefaction remain at least $3 \mathrm{hr}$ after the mainshock but no more than $24 \mathrm{hr}$.

The nonlinear simulation shows a strong reduction of the shear modulus during the largest ground shaking before the liquefaction happened. The observed horizontal peak acceleration was only about $25 \%$ of the peak acceleration expected from the linear theory, while the observed vertical peak acceleration is very similar to the vertical peak acceleration predicted by the linear theory. The inclusion of this effect helps to explain the complex distribution of the peak accelerations in the Kobe area. It also shows the necessity of considering this effect in the seismic risk analysis.

\section{Acknowledgments}

We thank Dr. Tomotaka Iwata for his helpful suggestions. We are also grateful to L. E. Perez-Rocha for providing the code with which to compute the nonlinear simulation. Detailed comments from David J. Wald and two anonymous reviewers helped us to improve the manuscript. The acceleration records of the vertical array in Port Island were kindly provided by Kobe City. The program used for genetic algorithms was GENESIS version 5.0 coded by John J. Grefenstette.

\section{References}

Aguirre, J. and K. Irikura (1995). Preliminary analysis of non-linear site effects at Port Island vertical array station during the 1995 Hyogokennambu earthquake, J. Nat. Disaster Sci. 16, no. 2, 49-58.

Aguirre, J., K. Irikura, and K. Kudo (1994). Estimation of strong ground motions on hard rock and soft sediment sites in Ashigara valley using the empirical Green's function method, Bull. Disas. Prev. Res. Inst., Kyoto Univ. 44, 45-68.

Ansary, M. A., F. Yamazaki, T. Katayama, and I. Towhata (1995). Analysis of ground motions at liquefied site during the 1995 Great Hanshin Earthquake, 23rd Earthquake Eng. Workshop, JSCE, 277-280.

Beresnev, I. A., K.-L. Wen, and Y. T. Yeh (1995). Nonlinear soil amplification: its corroboration in Taiwan, Bull. Seism. Soc. Am. 85, 496515.

Chin, B.-H. and K. Aki (1991). Simultaneous study of the source, path, and site effects on strong ground motion during the Loma Prieta earthquake: a preliminary result on pervasive nonlinear site effects, Bull. Seism. Soc. Am. 81, 1859-1884.

Cubrinovski, M. and K. Ishihara (1996). Assessment of the Kobe Port Island liquefaction through analytical simulation of the vertical array records, Proc. of the Special Conference on Great Hanshin-Awaji Earthquake Disasters, Japan Society of Civil Engineers, January, Tokyo, 157-164.

Development Bureau, Kobe City (1991). Report of the soil investigation and installment of strong motion accelerograph (in Japanese).

Development Bureau, Kobe City (1995). Report of the investigation of ground variation in reclaimed land during Hyogo-ken Nanbu earthquake (Port Island, Rokko Island) (in Japanese).

Elgamal, A.-W., M. Zeghal, and E. Parra (1996). Liquefaction of reclaimed Island in Kobe, Japan, J. Geotech. Eng., ASCE 122, 39-49.

Hardin, B. O. and V. P. Drnevich (1972). Shear modulus and damping in soils: design equations and curves, Proc. Am. Soc. Civil Eng., J. Soil Mech. Foundations Div. 98, 667-692.

Idriss, I. M. and H. B. Seed (1968). Seismic response of horizontal soil layers, J. Soil Mech. Foundations Div. ASCE 96.

Ishihara, K., S. Yasuda, and H. Nagase (1996). Soil characteristics and ground damage (special issue), Soils Foundations January 1996, 109-118.

Iwasaki, Yoshinori (1987). Dynamic properties of soils. Lecture note of training course for the Kansai section of Japanese Geotechnical Society, November 1987, 381-398 (in Japanese).

Joyner, William B. and Albert T. F. Chen (1975). Calculation of nonlinear ground response in earthquakes, Bull. Seism. Soc. Am. 65, 1315-1336.

Ordaz, M. and E. Faccioli (1994). Site response analysis in the valley of Mexico: selection of input motion and extent of non-linear soil behaviour, Earthquake Eng. Struct. Dyn. 23, 895-908.

Perez-Rocha, L. E. and F. J. Sanchez-Sesma (1992). Hybrid non-linear response of soft soils, Proc. 10th World Conf. Earthquake Eng. 2, 973-979.

Report of the Japanese Society of Soil Mechanics (1996). Report on an investigation of Hanshin-Awaji great earthquake disaster (in Japanese).

Sato, K. T. Kokusho, M. Matsumoto, and E. Yamada (1996). Nonlinear seismic response and soil property during strong motion (special issue), Soils Foundations January 1996, 41-52. 
Satoh, T., T. Sato, and H. Kawase (1995). Nonlinear behavior of soil sediments identified by using borehole records observed at the Ashigara valley, Japan, Bull. Seism. Soc. Am. 85, 1770-1789.

Silva, W. (1976). Body Waves in a layered anelastic solid, Bull. Seism. Soc. Am. 66, 1539-1554.

Sugito, M. and H. Kameda (1990). Nonlinear soil amplification model with verification by vertical strong motion array records, Proc. 4th U.S. Natl. Conf. Earthquake Eng. I, 555-564.

Terzaghi, K. (1956). Theoretical Soil Mechanics, Wiley, New York.

Vucetic, M. and R. Dobry (1991). Effect of soil plasticity on cyclic response, J. Geotech. Eng. ASCE 117, 89-107.

Yoshida, N., S. Nakamura, and I. Suetomi (1995). Nonlinear response of ground and its evaluation during the 1995 Hyogoken-nanbu earthquake, Proc. of the 23rd Symposium of Earthquake Ground Motion, Architec. Institute of Japan, Tokyo, 39-52 (in Japanese, with English abstract).

Disaster Prevention Research Institute

Kyoto University

Gokasho, Uji

Kyoto 611, Japan

Manuscript received 13 November 1996. 